\title{
Thermal Performance Evaluation of Wax Type Solar Distillation System
}

\author{
Anupam Alok Chaturvedi ${ }^{1}$, Shweta Ashish Karnik ${ }^{2}$ Dr. Sadanand Namjoshi ${ }^{3}$ \\ ${ }^{I}$ (Mechanical, Vadodara Institute of Technology, India) \\ ${ }^{2}$ (Mechanical, K.J. Institute of Technology, India) \\ ${ }^{3}$ (Mechanical, K.J. Institute of Technology, India)
}

\begin{abstract}
The alternative energy sources are new option in front of world to overcome energy crisis and pollution related issues. The solar energy, wind energy and bio mass are three major sources and out of these three energy sources solar energy is the easiest source to extract useful energy because the wind energy can be useful particularly in coastal area where there is high wind velocity and energy extraction bio mass needs either chemical conversion or thermo chemical conversion process. The objective of present work is to developed solar distillation system consists of wax as phase change material to improve the thermal performance.
\end{abstract}

Keywords: Alternative energy sources, solar energy, solar distillation

\section{Introduction}

The current industrial growth and environmental impacts show that solar energy for solar thermal power plants is the most promising of the unconventional energy sources. The most common commercially available solar power plants use parabolic trough concentrators. Solar energy is an exhaustible source of energy potentially capable of meeting a significant portion of all nations Future energy needs with a minimum of adverse environmental consequences. The current industrial growth and environmental impacts shows that solar energy for solar thermal plant is the most promising of unconventional energy source. The solar energy option has been identified as one of the promising alternative source for future. Solar thermal utilization is of great importance for environmental protection and conventional energy saving. In the next few years it is expected that millions of households in the world will be using solar energy as the trends in USA and Japan show. This energy is used for: Cooking/Heating, Drying/Timber seasoning, Distillation, Electricity/Power generation, Cooling, Refrigeration. Some of the gadgets and other devices: Solar cooker, Flat plate solar cookers, Concentrating collectors, Solar hot water systems (Domestic and Industrial), Solar pond, Solar hot air systems, Solar Dryers, Solar timber kilns, solar stills, Solar photovoltaic systems, Solar pond, Concentrating collectors, Power Tower, Air conditioning, Solar collectors, coupled to absorption, Refrigeration systems.

\section{Solar Distillation}

Distilled water is water that has many of its impurities removed through distillation. Distillation involves boiling the water and then condensing the steam into a clean container. There are multiple types of distillation, but all of them depend on separating components of a mixture based on their different boiling points. In a nutshell, water is heated to its boiling point. Chemicals that boil off at a lower temperature are collected and discarded; substances that remain in a container after the water evaporates also are discarded. The water that is collected thus has a higher purity than the initial liquid.

Solar distillation is the process in which the sun evaporates the water from lakes, rivers, oceans and other surface waters leaving salts and other minerals behind. This evaporated water eventually reaches the upper atmosphere where it recondenses as clouds and precipitates back to the land. This is the basic principle behind the use of solar energy for distillation the solar distillation method is fairly simple and is pretty much selfoperating. Saline water is supplied either continuously or intermittently to a pool ranging in depths of approximately 1 inch to 1 foot. The bottom of the pool has a black surface which absorbs solar energy. The discards salts exit through a drain. A transparent cover composed of glass sheets or plastic film is supported above. These are arranged so that the surfaces slope downward into small troughs at their lower edges. MiqdamT.Chaichan et. al [1] developed paper investigates usage of thermal energy storage extracted from concentrating solar heater for water distillation. M. Umamaheswaran et. al [2] focused on details the construction, testing and analysis of parabolic trough collector/reflector configuration for small scale domestic purpose water distillation application. Alpesh Mehta et. al [3] performed experiment on solar distillation system. The designed model produces 1.5 litres of pure water from 14 litres of dirty water during six hours. Sunil Jayant Kulkarni et. al [4] present review summarizes the research carried out on solar distillation. Various investigators have investigated the solar distillation with various storage or phase change materials, using different dyes and various numbers of effects to improve the effectiveness and efficiency. Tadahmun 
Ahmed Yassen et. al [5] studied experimental and theoretical study has been conducted to determine the thermal efficiency of a parabolic trough solar collector. The solar collector which consists of a parabolic section, the reflector and absorber tube, is installed in the focus line of the surface reflector. KHALID GUISSI et. al [6] developed a new design of a greenhouse solar distiller with parabolic trough in order to increase the performance of the distiller and subsequently obtaining a important distillate flow. Jamil Al Asfara et. al [7]studied a six meter long parabolic trough collector was designed, constructed and tested to assess its performance. The result of this work proves the efficiency and potential of such green energy sources for both local society and decision-makers. M.Gowtham et. al [8] focused desalination which is done by concentrating solar thermal energy through a parabolic trough concentrator. Studies were made improving the evaporation rate of the system. The parabolic concentrator solar distiller with latent heat storage material and energy storing materials are studied.

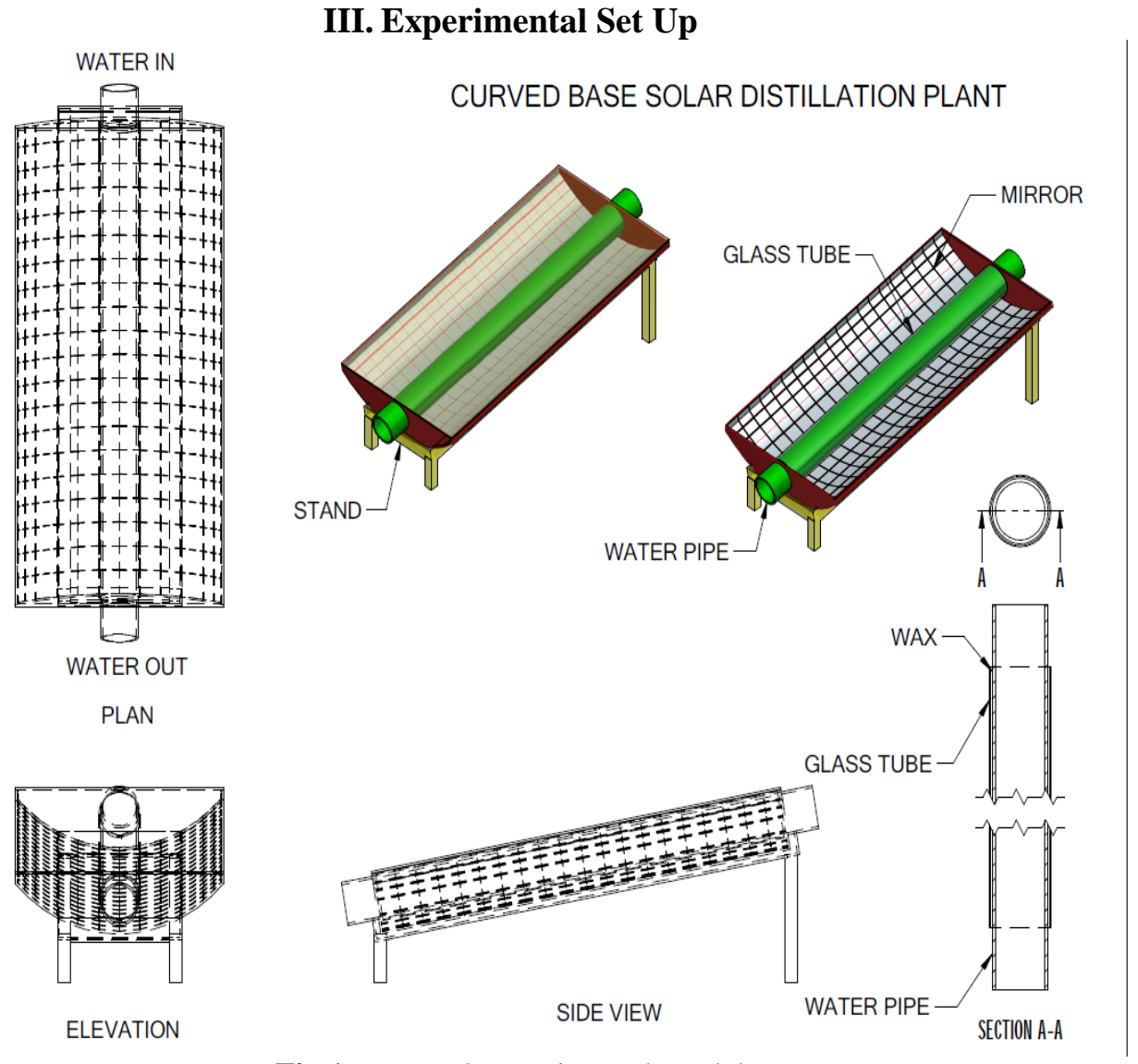

Fig 1 Proposed Experimental Model

\section{Experimental Detail}

The parabolic trough based on equation $y=f x^{2}$ where $f=$ focal length. First of all assuming the value of focal length $\mathrm{f}$ in case of both set up and then an by variing $\mathrm{x}$, $\mathrm{y}$ can be obtained. After finalisation of dimension the copper pie of 1" diameter placed at focal pint and curvature of parabola having mirror pieces stick on the surface. Due solar radiation focusing on the copper pie when water wll eneters in the pipe at low flow rate it get converted into steam and that steam will be condensed at later stage to obtain pure water. The wax will be filled in mild steel tube.

\section{List of Compoents}

$>$ Parabolic Trough

$>\mathrm{K}$ type thermocouples with indicators

$>$ Mirror pieces

$>1$ " copper Tube

$>$ Condensation Unit 


\section{Constructional Detail of Experimental Set Up}

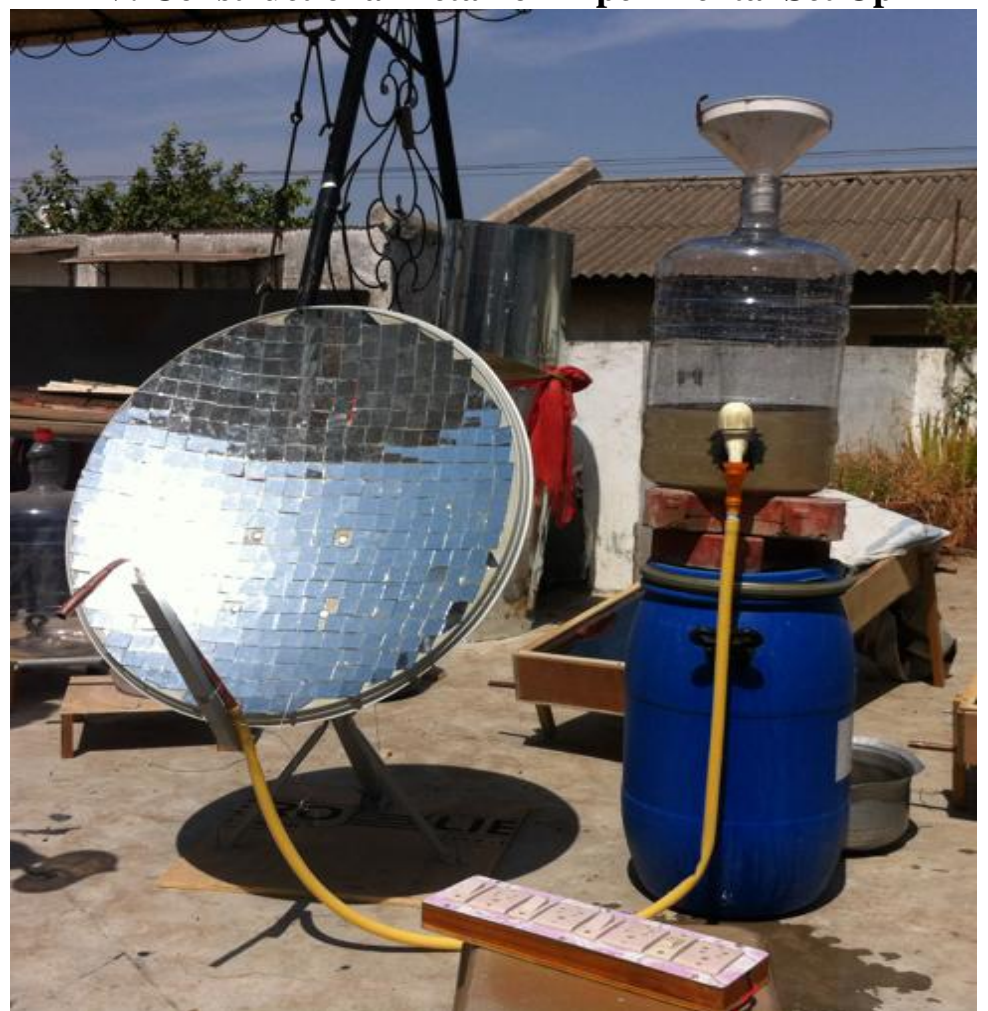

Fig 2 Actual Experimental Model

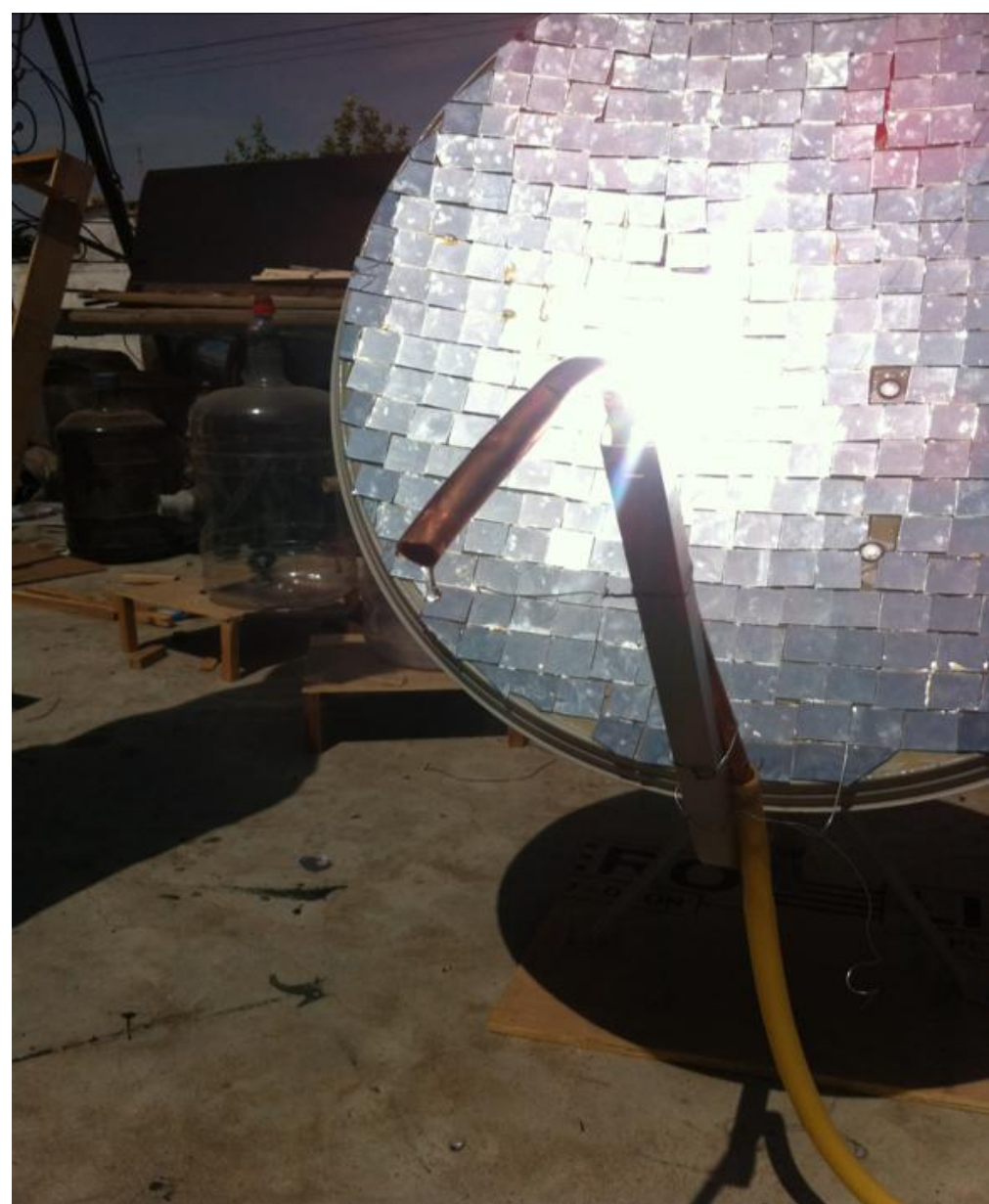

Fig 3 Location of Focal Point 


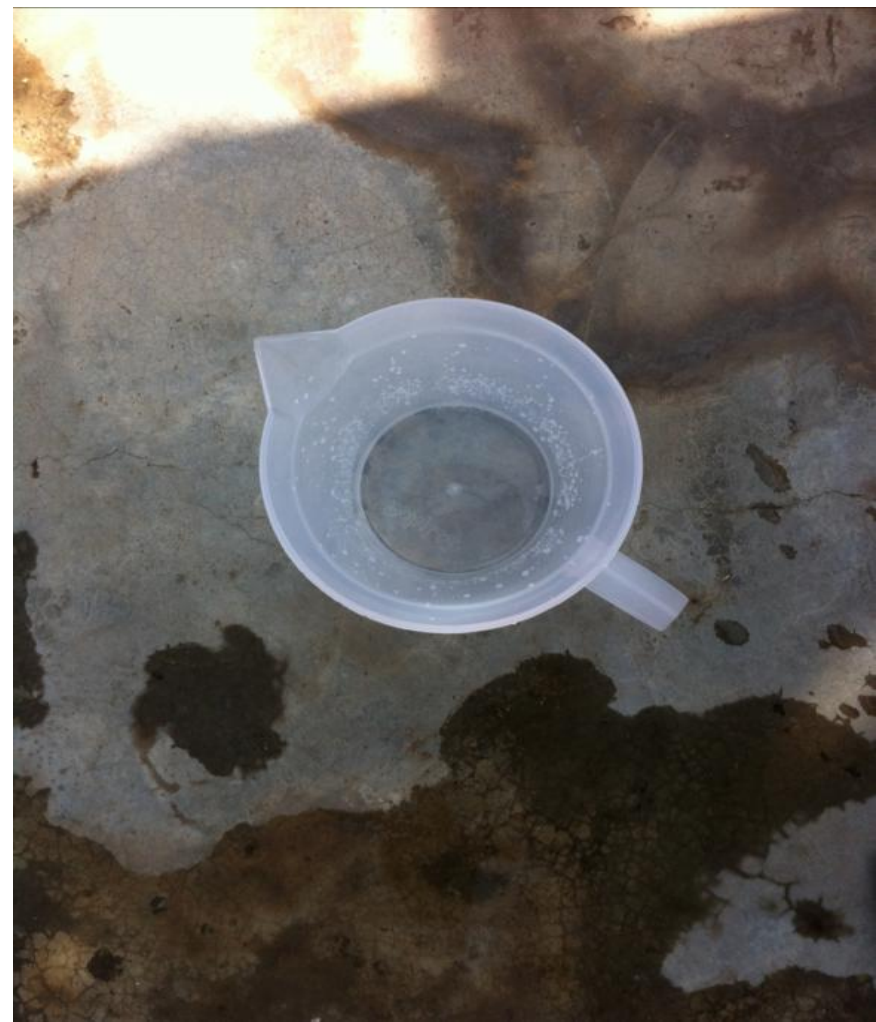

Fig 4 Distilled Water

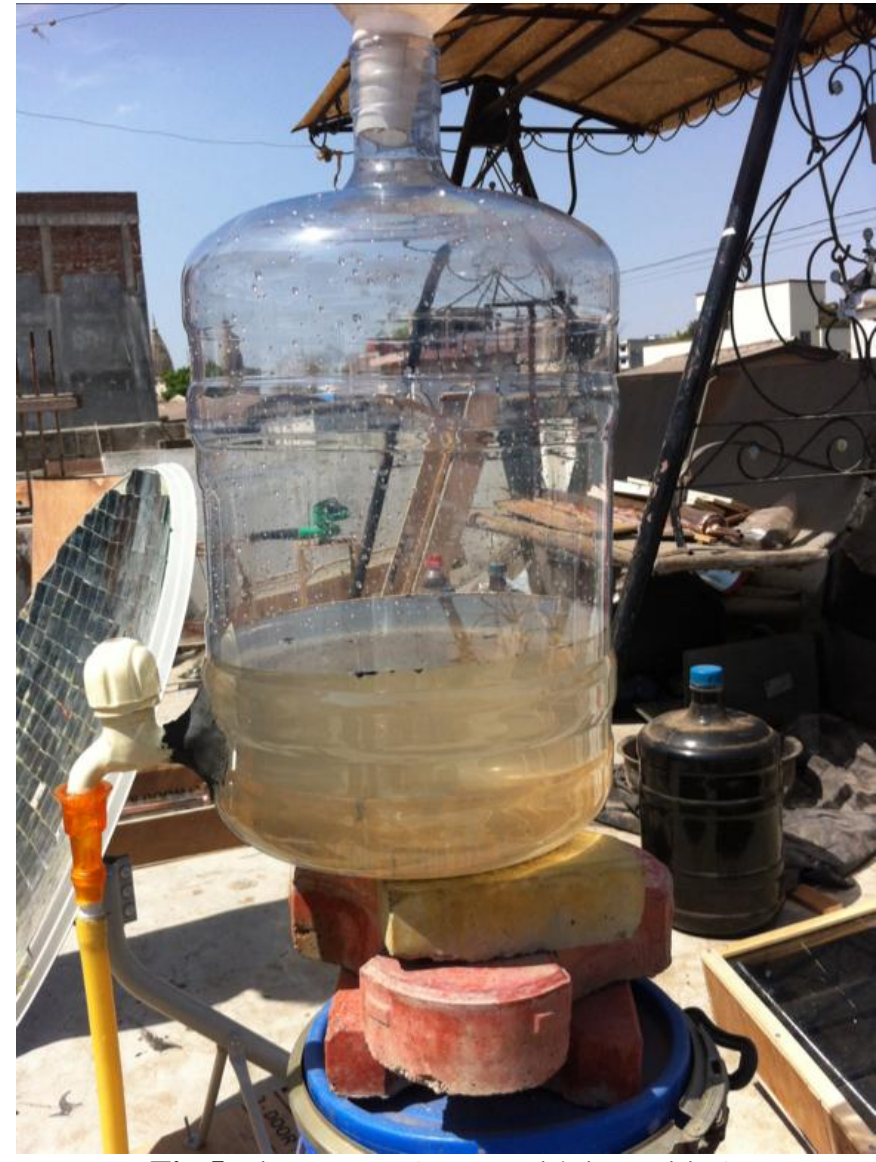

Fig 5 Dirty Water (Water with impurities) 


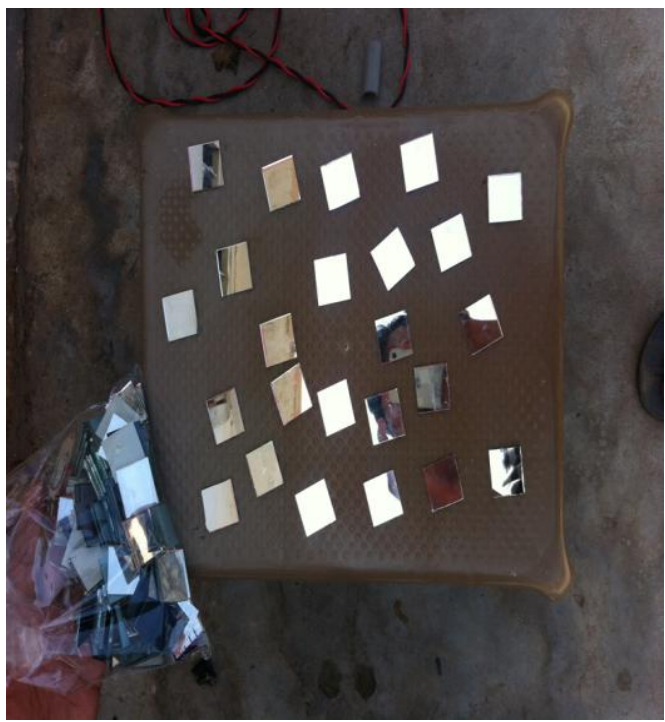

Fig 6 Mirror Pieces 1" X 1"

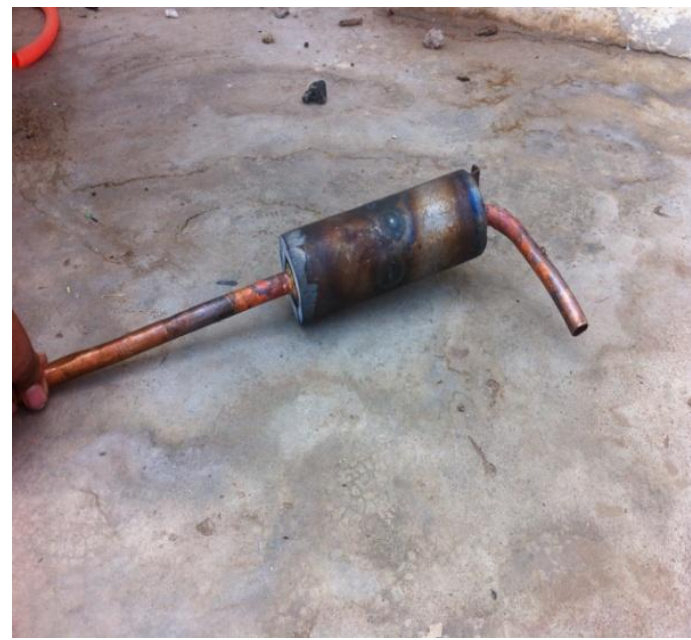

Fig 7 Copper Tube with Wax Box

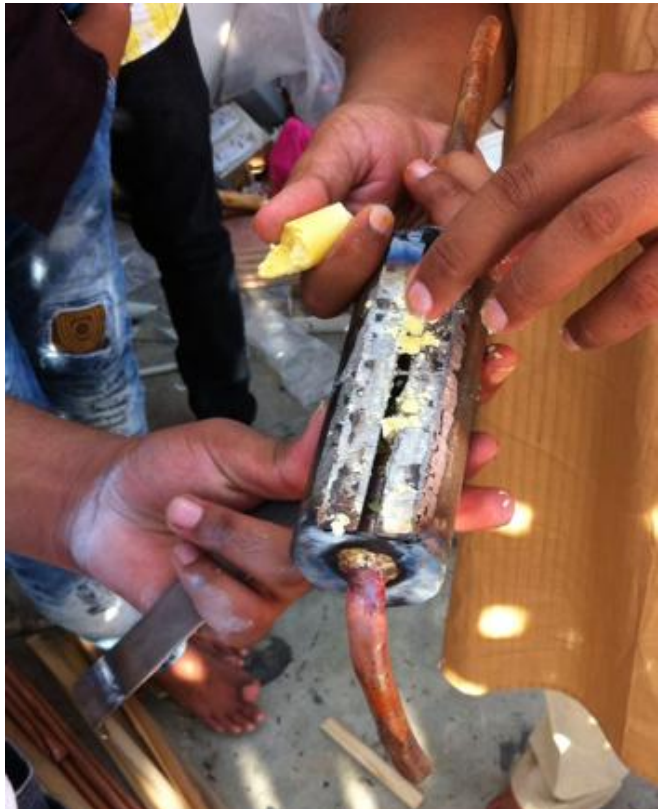

Fig 8 Filling of Wax in the Wax Box 


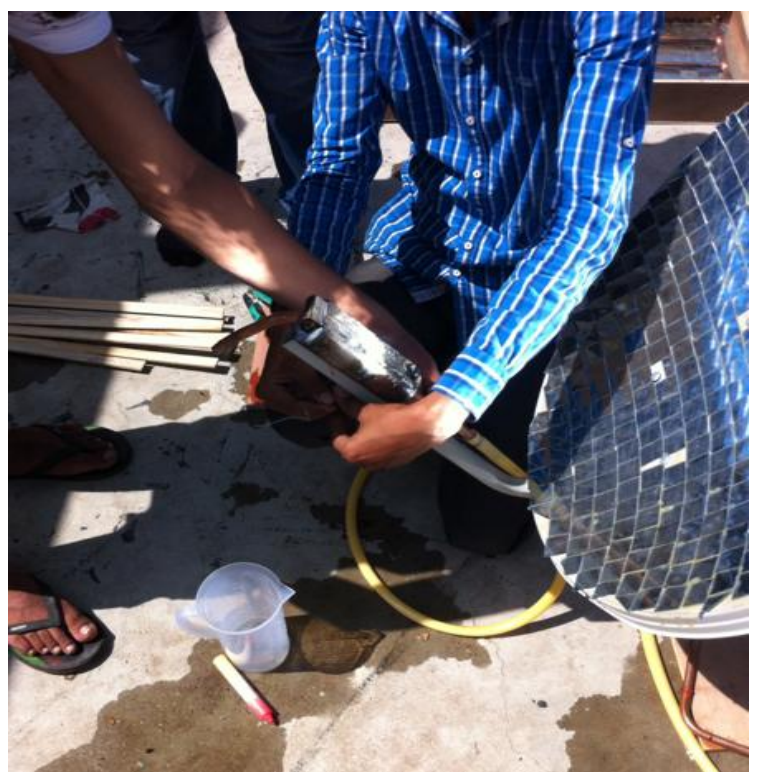

Fig 9 Setting of Wax box at Focal Point

\section{Result And Discussion}

After performing the experiments on present set up following observations have been obtained.

Table 1 Observation Table

\begin{tabular}{|c|c|c|}
\hline & \multicolumn{2}{|c|}{ With Wax } \\
\hline Time & $\begin{array}{c}\text { Temperature at Focal } \\
\text { Point }\end{array}$ & $\begin{array}{c}\text { Temperature of Water in } \\
\text { Flask }\end{array}$ \\
\hline 0 & 36 & 36 \\
\hline 3 & 87 & 44 \\
\hline 6 & 98 & 51 \\
\hline 9 & 112 & 54 \\
\hline 12 & 135 & 58 \\
\hline 15 & 150 & 62 \\
\hline
\end{tabular}

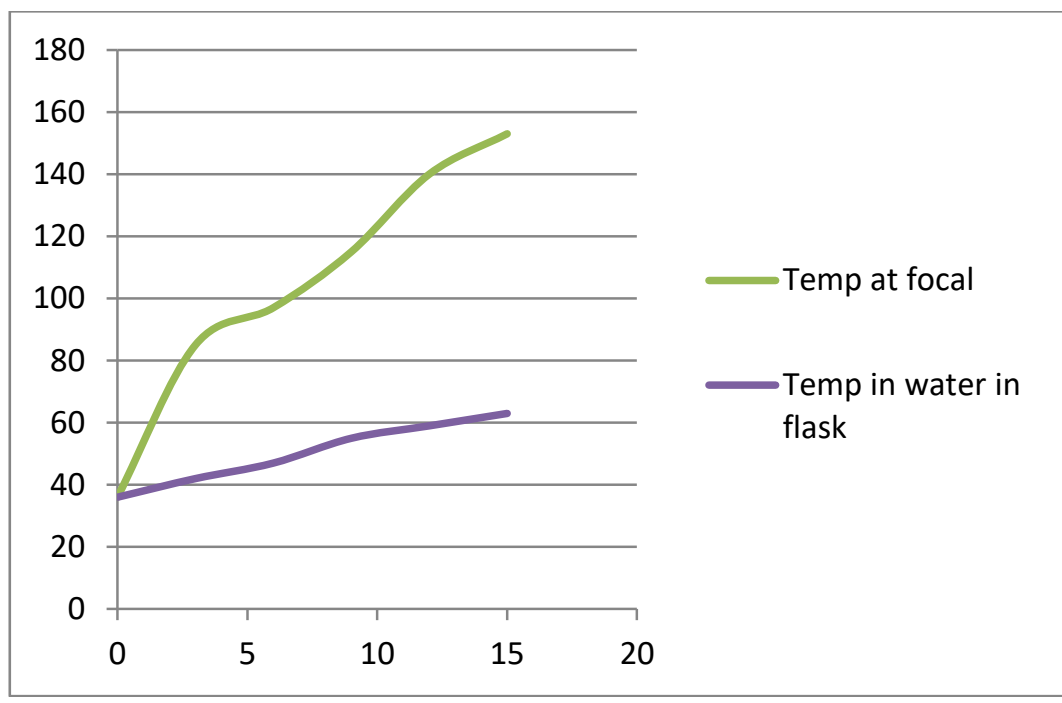

Fig 10 Temperature Variation with respect to time

From the observation table it is clear that due to melting of wax in a later stage heat is released which leads to increase the temperature of water in the flask. At the focal point the temperature is more than the boiling point of water and so when water reaches at the focal point get immediately evaporated into steam and due to density difference the impurities which are present in the water drain back in the water tank. The $\mathrm{K}$ type thermocouples are used to measure the temperature of water and at focal point. The wax is used because as and when the focal point will change its location the latent heat of wax can be utilized to heat the water. 


\section{Conclusion}

From the present work is clear that the thermal performance of distillation system can be improved by adding more wax but initially it reduces the temperature of water which may leads to collection of water with some impurities.

\section{References}

[1]. Miqdam T.Chaichan, HusseinA.Kazem, Water solar distiller productivity enhancement using concentrating solar water heater and phase change material (PCM), Case Studies in Thermal Engineering 5(2015)151-159

[2]. M. Umamaheswaran, Solar Based Distillation System For Domestic Application, Ninth International Water Technology Conference, IWTC9 2005, Sharm El-Sheikh, Egypt

[3]. Alpesh Mehta, Arjun Vyas, Nitin Bodar, Dharmesh Lathiya, Design of Solar Distillation System, International Journal of Advanced Science and Technology Vol. 29, April 2011

[4]. Sunil Jayant Kulkarni, Solar Distillation: A Review, International Journal of Research (IJR) Vol-1, Issue-11 December 2014

[5]. Tadahmun Ahmed Yassen, Experimental and Theoretical Study of a Parabolic Trough Solar Collector, Anbar Journal for Engineering Sciences 2012

[6]. Khalid Guissi, Abdelmoumen Tabyaoui1, Mohamed Harmouchi, Azeddine Mouhsen, El Mostafa Oualim, Abdellah Boulal, new design of a greenhouse solar distiller coupled with parabolic trough and the energy balance of this system, journal of science and arts year 15, no. 2(31), pp. 181-190, 2015

[7]. Jamil Al Asfar, Osama Ayadi and Ahmed Al Salaymeh, Jamil Al Asfar, Osama Ayadi and Ahmed Al Salaymeh, Design and Performance Assessment of a Parabolic Trough Collector, Jordan Journal of Mechanical and Industrial Engineering, Volume 8 Number 1, February. 2014, 1- 5

[8]. M.Gowtham, M.Sharath Chander, K.V.Sri Saila Mallikarujanan, and N.Karthikeyan, Concentrated Parabolic Solar Distiller with latent heat storage capacity, International Journal of Chemical Engineering and Applications, Vol. 2 , No. 3 , June 2011 